\title{
Free vibration induced by internal flow in cantilevered pipe under different parameters
}

\author{
Dahmane Mouloud $^{\mathrm{a}}$, Samir Zahaf ${ }^{* \mathrm{~b}}$,Mawhoub Soubih ${ }^{\mathrm{c}}$, Benkhetab Mohamed ${ }^{\mathrm{d}}$, Djilali \\ Boutchicha $^{\mathrm{e}}$ \\ ${ }^{\mathrm{a}, \mathrm{e}}$ LMA, Mechanical Engineering Department, USTO-MB, BP 1055 El Menaour, Oran \\ 31000, Algeria \\ $\mathrm{b}^{*}$ Department of Technology, University of Djilali Bounaama-KhamisMeliana, AinDefla- \\ Algeria. \\ ${ }^{c}$ Labortory of Mechanics and Energy, Chlef University HassibaBenbouali, Chlef, Algeria. \\ ${ }^{\mathrm{d}}$ Mechanical Engineering Department, Mostaganem University-AbdelhamidIbnBadis. \\ Email:dahmanemoul@gmail.com, boutchicha@hotmail.com,soubih.mihoub@gmail.com, \\ bkhmohamed@yahoo.fr \\ *Corresponding author: samir.zahaf@univ-dbkm.dz, zahafsamir1983@gmail.com
}

In this paper, the natural frequencies of a fluid conveying pipe and critical velocities are obtained with finite element method (FEM).By discretizing the pipe wall and fluid, starting from beam type with two degrees of freedom per node. We determine the equation of motion from the fluid-structure coupling using Lagrange energy principle. Parameters frequencies are calculated by using a program developed on MATLAB. The results are compared with those predicted by the differential transformation method (DTM). Stability and instability properties are analyzed after calculating the natural frequencies and the fluid critical velocity in terms of various parameters.

Keywords: Fluid conveying pipe, Natural frequency, Velocity, Foundation, FEM, MATLAB, Instability.

\section{Introduction}

When a structure is contacted with a fluid, the elastic compartment undergoes a significant change; the increase of the natural frequencies observed during interaction of fluid with structure can even affect the system stability. Study of this subject is much ramified,

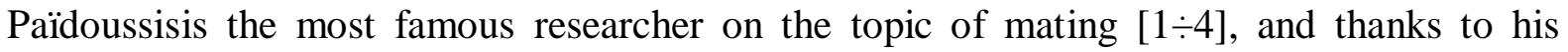
research we obtained the linear and non-linear equation of the pipes motion under the

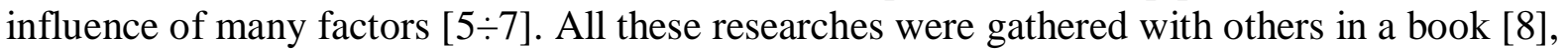

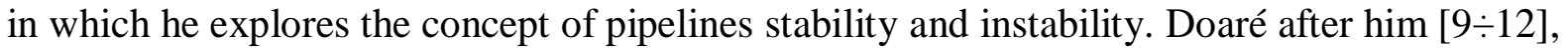
he touched better on the issue of instability, we find in his work that he studied instability in its two types (dynamic, static), and that is by calculating the frequencies in terms of the fluid critical velocity. A significant amount of research has been carried out the dynamics of cantilevered pipe-conveying fluid, by means of linear mathematical models [8]. And there are other work in the same context, analytical,suchasGalerkinmethod [13, 14], semi-analytical,

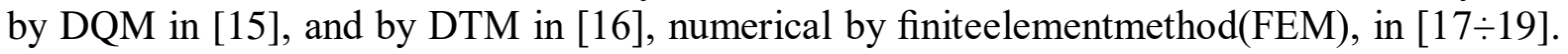
All these studies did not take into consideration the concept of the range (field) instability as well as the analysis, and the instability parameters, which constitutes an obstacle and challenge for engineers, especially in theheat exchangersas nuclear production, industry pipelines, fuel pipes in high duty engines, hydropower systems, and solution mining applications. 
In the present study, calculation methods have been developed for the free vibrations analysis of cantilevered pipe conveying fluid.The numerical methods were developed, modeling of structure (pipe)-incompressible fluid, and was conducted by the standard finite element method,using beam type with two degrees of freedom per node. The proper frequencies and critical velocity of the system are calculated using a program developed on MATLAB. This allows us to study instability and discover its most important characteristics.

\section{Differential equation of motion}

The problem to be considered is the vibration analysis of a fluid conveying pipe system on anelastic foundation Winkler-model. The derivation of the equation is based onBernoulliEuler elementary beam theory. The physical model of system is shown in figure 1 (a), figure 1 (b) shows forces on fluid element,figure 1 (c)shows forces and pipe elementmoment.

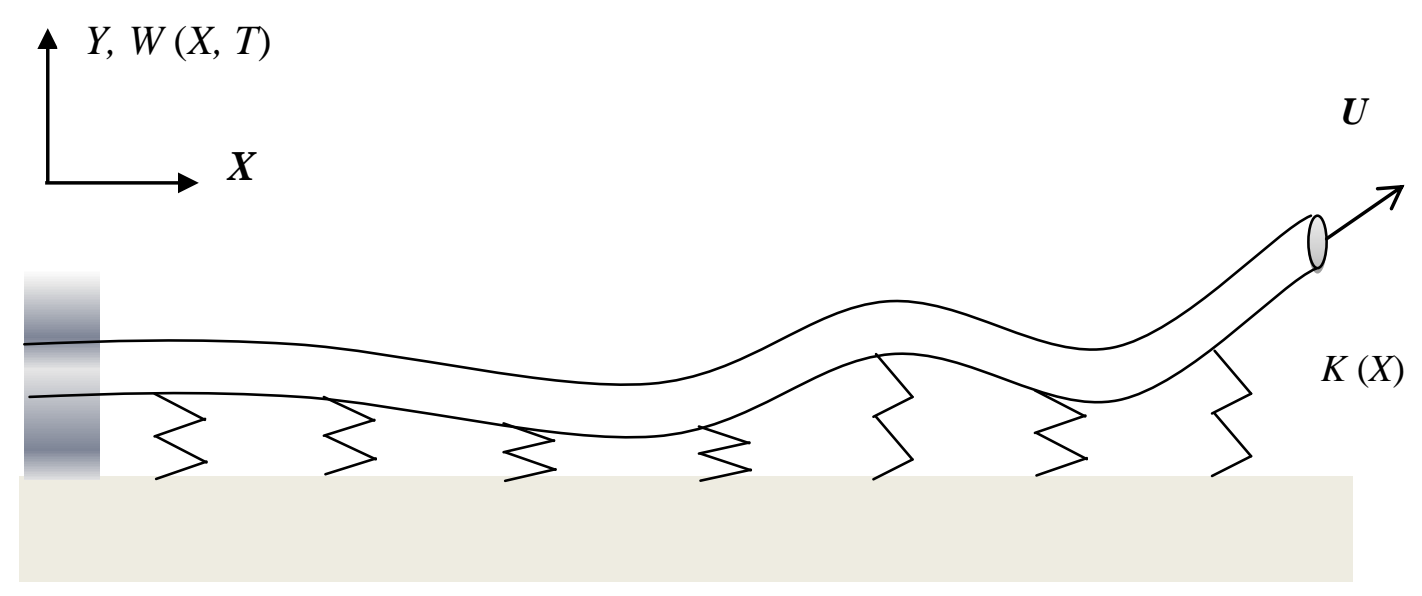

(a)

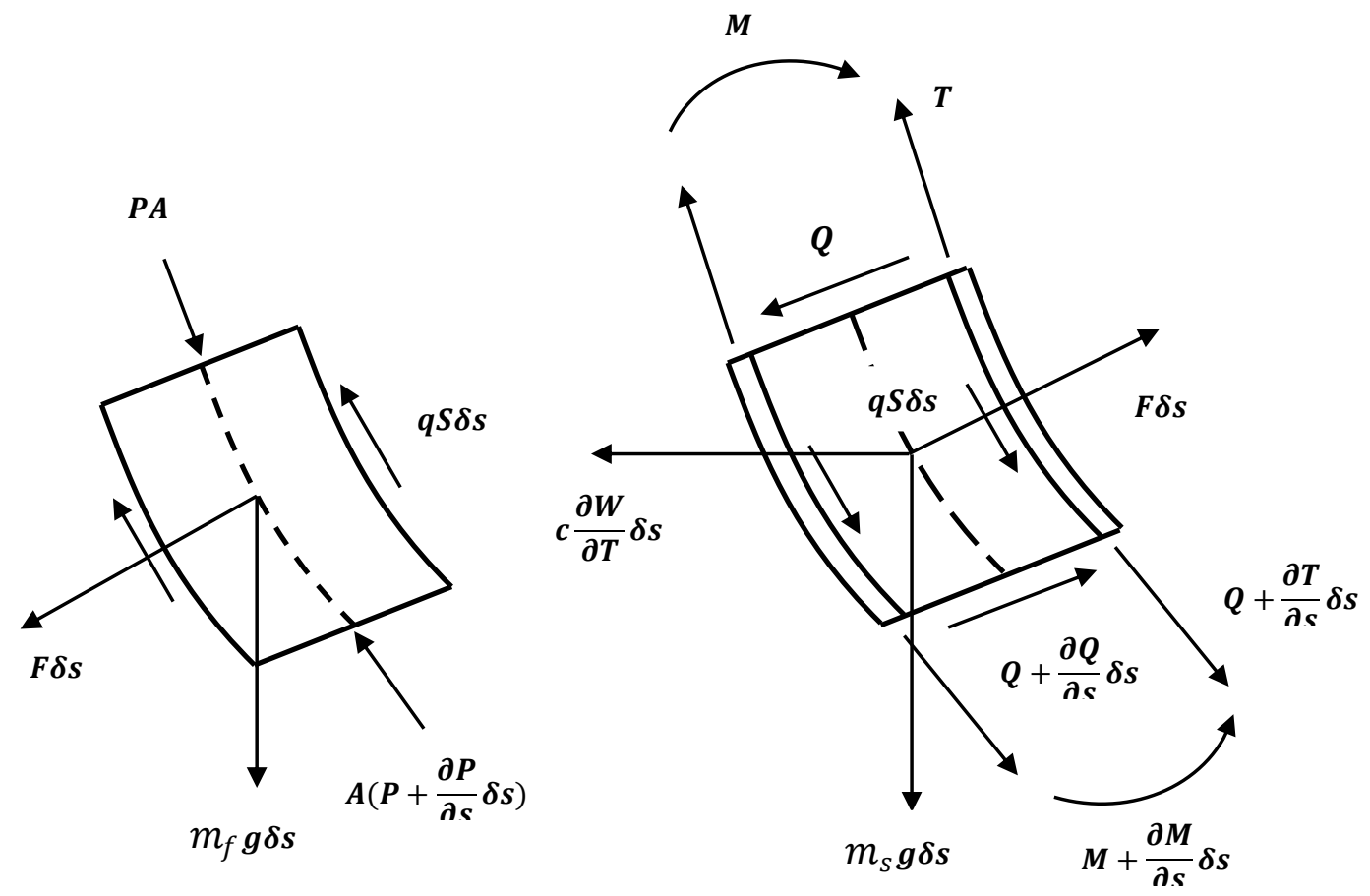

(b)

(c)

Figure 1: (a) Cantilevered pipe-conveying fluid resting on anfoundation elastic Winklertype, (b) forces on fluid element; (c) forces and moments on pipe element $\delta s[8]$. 
The equation for conveying pipe carryingfluid on a Winkler elastic foundation is given as [19],

$$
E I \frac{\partial^{4} Y}{\partial X^{4}}+m_{f} U^{2} \frac{\partial^{2} Y}{\partial X^{2}}+2 m_{f} U \frac{\partial^{2} Y}{\partial X \partial T}+\left(m_{s}+m_{f}\right) \frac{\partial^{2} Y}{\partial T^{2}}+K Y=0
$$

Where, the pipe is long and straight $L$ conveyinganincompressiblefluidwithsteadyspeed $U$; the motions are small $\delta s$. The elastic foundation Winkler-model is $K Y, m_{s}$ and $m_{f}$ the massesperunitlengthofthe pipeandthefluid, respectively. The Boundary conditions are,

$$
\begin{aligned}
& \left.Y\right|_{X=0}=\left.\frac{\partial Y}{\partial X}\right|_{X=0}=\left.\frac{\partial^{2} Y}{\partial X^{2}}\right|_{X=L}=\left.\frac{\partial^{3} Y}{\partial X^{3}}\right|_{X=L}=0 \\
& \left.y\right|_{x=0}=\left.\frac{\partial y}{\partial x}\right|_{x=0}=\left.\frac{\partial^{2} y}{\partial x^{2}}\right|_{x=1}=\left.\frac{\partial^{3} y}{\partial x^{3}}\right|_{x=1}=0
\end{aligned}
$$

Where, the non-dimensional parameters [8], we obtain,

$$
\begin{gathered}
x=X / L, \quad y=Y / L, \quad t=\left(E I /\left(m_{f}+m_{s}\right)^{1 / 2}\right) T / L^{2}, \beta=m_{f} /\left(m_{f}+m_{s}\right), \\
u=U L\left(m_{f} / E I\right)^{1 / 2}, k=K L^{2} / E I \\
y(x, t) \\
x \quad \underset{r}{\longrightarrow}
\end{gathered}
$$

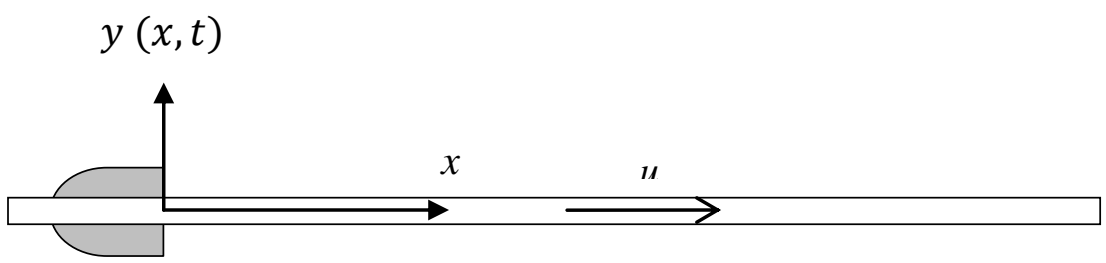

Figure 2: Clamped-free Pipe with fluid

Where, the potential (deformation) energyand the kinetic energy of the solid element expressed by,

$$
\begin{gathered}
V_{1}=\frac{1}{2} \int_{0}^{L} E I\left(\frac{d^{2} W}{d X^{2}}\right)^{2} d X(4) \\
E_{C s}=\frac{1}{2} \int_{0}^{L} m_{s} \frac{d^{2} W}{d T^{2}} d X(5)
\end{gathered}
$$

The kinetic energy of the fluid element can be expressed by[17],

$$
E_{C f}=\frac{1}{2} \int m_{f}\left(U \frac{d W}{d X}+\frac{d W}{d T}\right)^{2} d X(6)
$$

The potential energy over the length of elastic foundation can be expressed by[16,17],

$$
V_{2}=\frac{1}{2} \int_{0}^{L} K W^{2} d X(7)
$$

The equation of element deflection for straight two dimensional beam element could have the form [20],

$$
W(X, T)=\sum_{i=1}^{N} N_{i}(X) W_{i}(T)
$$

Where, $\left[N_{i}\right]$ represent the shape function and $W_{i}(T)$ is the function which represents the shape of the displacements and rotations at nodes, 


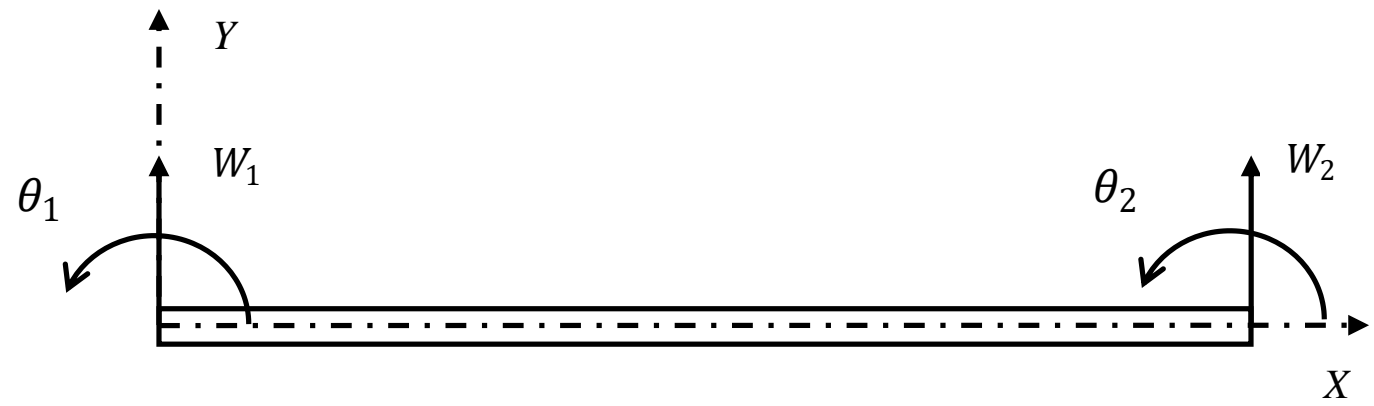

Figure 3:Beam element nodal displacements

Where,

$W_{1}, \theta_{1}, W_{2}$ et $\theta_{2}:$ are the displacements and rotations at the nodes,

Therefore, equation (8) becomes

$$
W(X, T)=N_{1}(X) W_{1}(T)+N_{2}(X) \theta_{1}(T)+N_{3}(X) W_{2}(T)+N_{4}(X) \theta_{2}(T)
$$

Forming shape functions,

Where, $0 \leq x \leq 1$

$$
\left\{\begin{array}{l}
N_{1}=1-3 x^{2}+2 x^{3} \\
N_{2}=L\left(x-2 x^{2}+3 x^{3}\right) \\
N_{3}=3 x^{2}-2 x^{3} \\
N_{4}=L x^{2}(x-1)
\end{array}\right.
$$

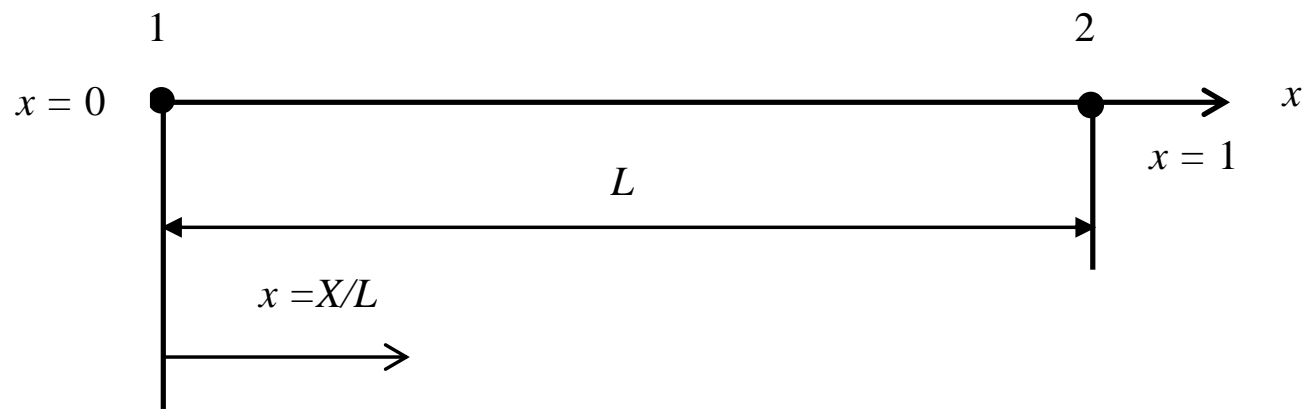

Figure 4:Reference element.

Lagrange'sprinciple

$$
\frac{d}{d T}\left(\frac{\partial E_{C}}{\partial \dot{q}_{i}}\right)-\frac{\partial E_{C}}{\partial \dot{q}_{i}}+\frac{\partial V}{\partial q_{i}}=0(11)
$$

The standard equation of motion in the finite element form is,

Where,

$$
[M]\{\ddot{q}\}+[C]\{\dot{q}\}+([K])\{q\}=0(12)
$$

$[M]=\left[M_{s}\right]+\left[M_{f}\right]$, elementary mass matrix of the system;

$[C]$, elementary damping matrix of the system;

$[K]=\left[K_{s}\right]-\left[K_{f}\right]$, elementary stiffness matrix of the system

Considering the displacement vector as,

$$
\{Q\}=\{E\} \cdot \exp (\lambda t)
$$

The governing equation of the system for fluid-structure coupling can be transformed into its state-space, 


$$
\left\{\left[\begin{array}{cc}
0 & \boldsymbol{I} \\
-M^{-1} K & -M^{-1} C
\end{array}\right]-\lambda\left[\begin{array}{cc}
\boldsymbol{I} & 0 \\
0 & \boldsymbol{I}
\end{array}\right]\right\}\left[\begin{array}{c}
\lambda\{E\} \\
\{E\}
\end{array}\right]=\left[\begin{array}{l}
0 \\
0
\end{array}\right]
$$

Where, $I$ is the identity matrix,

Complex conjugate eigen-values, $\lambda^{m}=R e^{m}+j \omega^{m}$,

The stability and instability of the system under consideration is determined by the sign of real part, and the natural frequencies values (the imaginary part ) of the complex eigen-value.

\section{Results and discussion}

In studying and analyzing the concept of instability, the fundamental natural frequency of a pipe decreases with increasing fluid velocity. There are certain cases where a decrease in this natural frequency can be very important and with large fluid velocities, the pipe may become unstable. Results will be discussed for various values of $\beta$, length $L$, elastic foundation $k$ (Winkler type), and the instability parameters for clamped-free pipe. The elastic modulus of pipe is $(E=207 \mathrm{GPa})$, pipe length is $(L=1 \div 2 \mathrm{~m})$, fluid density is $\left(m_{f}=1000 \mathrm{~kg} / \mathrm{m}^{3}\right)$, pipe density is $\left(m_{s}=7850 \mathrm{~kg} / \mathrm{m}^{3}\right)$, pipe thickness for $(\beta=0.1 \div 0.7)$ and the outer diameter of the pipe is $(0.03 \mathrm{~m})$.

\subsection{Mass ratio effect}

We calculated the natural frequency for first eigen modes of clamped-free pipe for mass ratios, according to the fluid speed, see the figures (5) and (6).

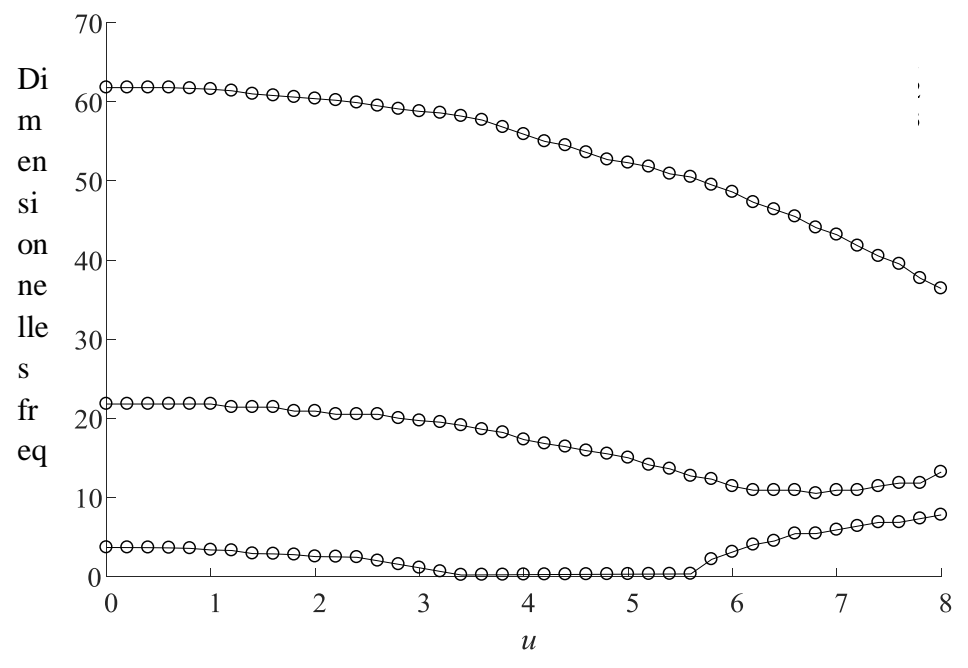

Figure 5: The imaginary component of the dimensionless frequency as a various values of fluid velocity $(u)$, for the lowest three modes of a clamped-free pipe conveying fluid, comparison DTM [16] (ooo) and FEM ( - ), $\beta=0.5$. 

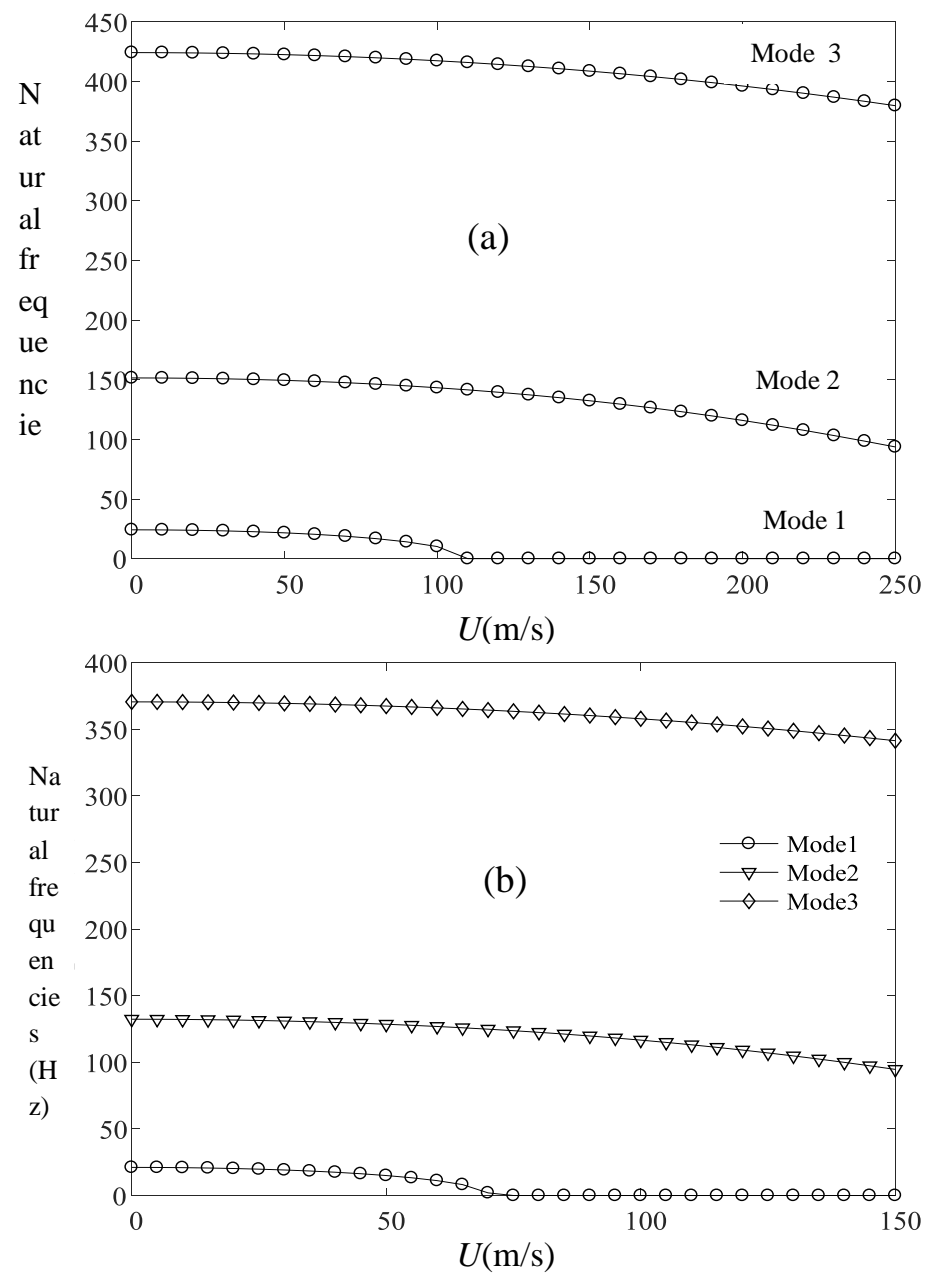

Figure 6: Naturel frequency $(\mathrm{Hz})$ for three proper modes on fluid velocity function of cantilevered pipe conveying fluid, $L=1$, (a) $\beta=0.3$, (b), $\beta=0.5$.

Firstly, the program has been validated with reference [16], by calculating the first three dimensionless frequency as a function of the fluid velocity for cantilevered pipe with internal flow, where $\beta=0.5$. The figure 5 shows that the results obtained numerically are similar to those obtained by the analytical approach. The rigidity of a fixed-free beam system is very low than the other boundary conditions, it is preferable to use a dimensioning by calculating the natural frequencies. The figure 6 shows that the free vibration of the clamped-free pipe under an internal flow is very sensitive to the variation of mass ratios.

\subsubsection{Length effect}

We calculated the frequency ofthe first three eigen-modes clamped-free pipe for two mass ratios, according to the fluid speed where $L=1.5 \mathrm{~m}$,see the figure (7).

We see in the figure 6 (a) that the first frequency is $25 \mathrm{~Hz}$, in the case of a fluid at rest (no flow) for a mass ration 0.3 , and for $\beta=0.5$ the first frequency is $22 \mathrm{~Hz}$, see figure 6 (b). the same remark for the second frequency which passes from $140 \mathrm{~Hz}$ to $150 \mathrm{~Hz}$, however for the third mode, the frequency passes from for $375 \mathrm{~Hz}$ for $\beta=0.5$ to $425 \mathrm{~Hz}$ for $\beta=0.3$. In this case the pipe comparable to a beam $(U=0)$ i.e. all its natural frequencies are imaginary. 


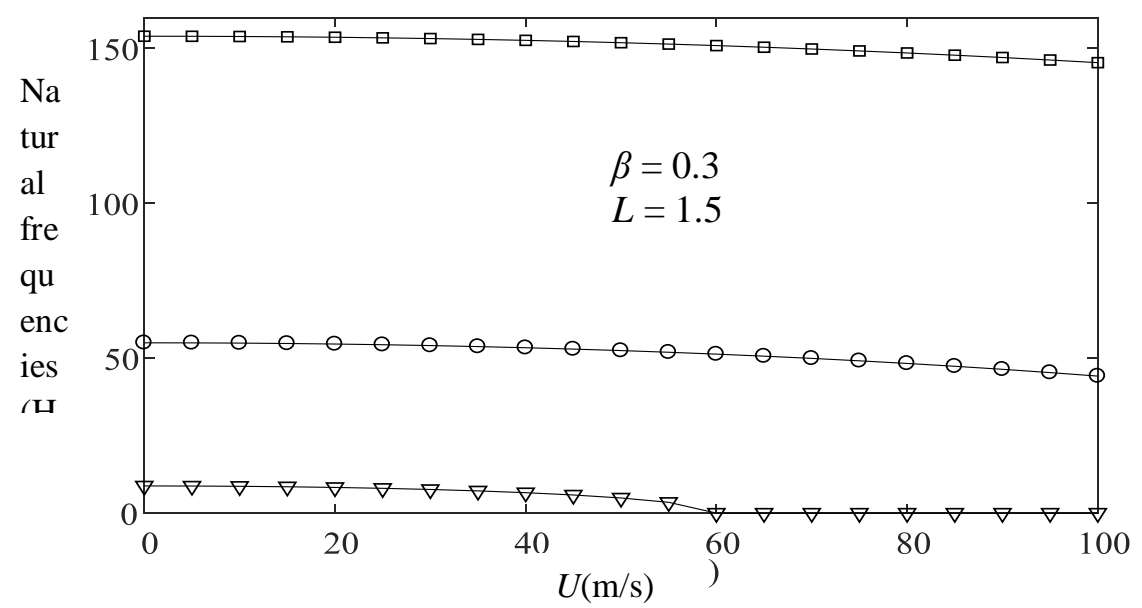

(a)

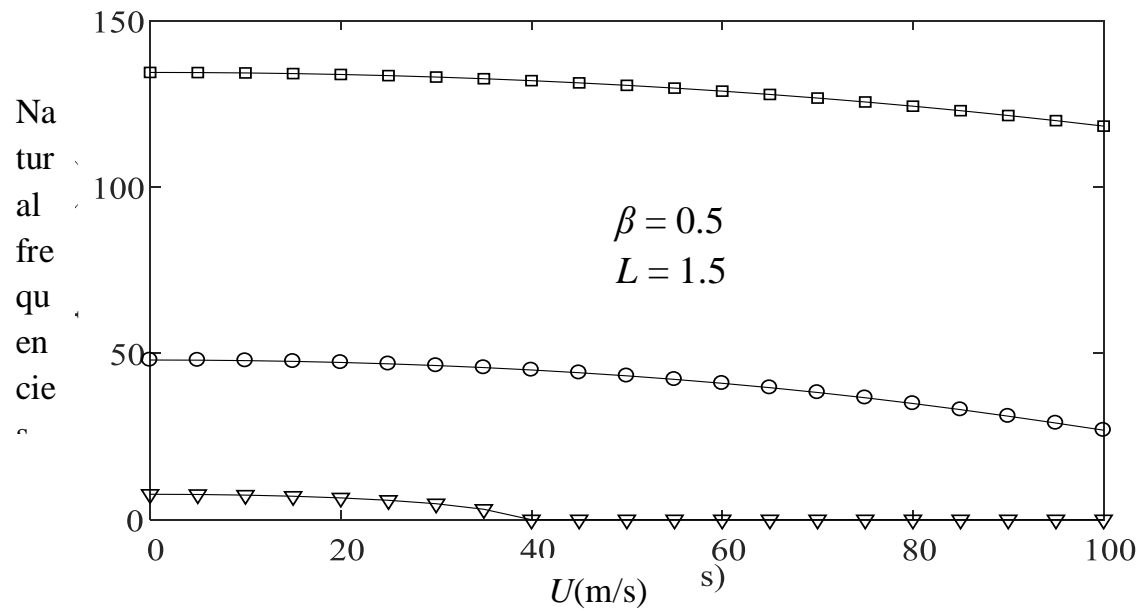

(b)

Figure 7: Effect of lengthand mass ratio on the natural frequency of the cantilevered pipe at different fluid velocities.

\subsubsection{Foundation effect}

We calculated the frequency of the first three eigen-modes clamped-free pipe on an elastic foundation with two low values, according to the fluid velocity, for twolengths, figure $8(L=1$ $\mathrm{m})$, figure $9(L=1.5 \mathrm{~m})$. 

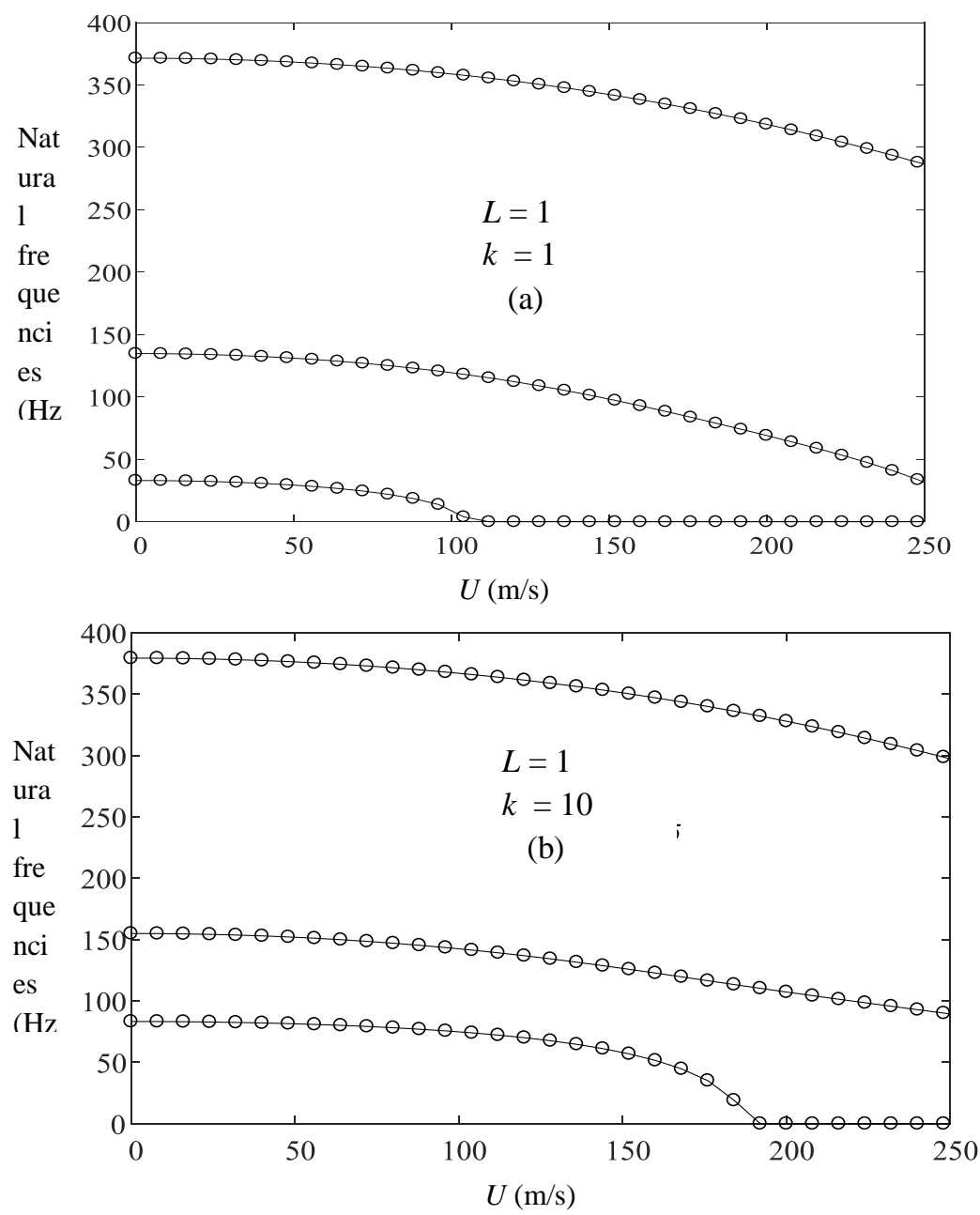

Figure 8: Effect of foundation stiffness on the natural frequency of the clamped-freepipe at different fluid velocities, (a) $k=1$, (b) $k=10, \beta=0.5$.

In the case of the flowing fluid, the first eigen modes are not similar for different mass ratio. The critical velocity is $76 \mathrm{~m} / \mathrm{s}$ for $\beta=0.5$, and for $\beta=0.3$, the critical speed is $110 \mathrm{~m} / \mathrm{s}$. when one increase the velocity, one observes firstof all a stabilization of the system, and all the natural frequencies see their imaginary part decreasing at the critical velocity of instability. We are now interested in the stability conditions of such system, we see in the figure $6(L=$ 1) and the figure 7 that the increase in the length quickly destabilizes the system which depends on $\beta$. The effect of the elastic foundation characterized by $(k)$, the variation of the first modes of pipe under aninternal flow is given by the figure 8 and the figure 9 for two lengths, where mass ratio is 0.5 . So thefigures show double effect of the foundation and the length. 

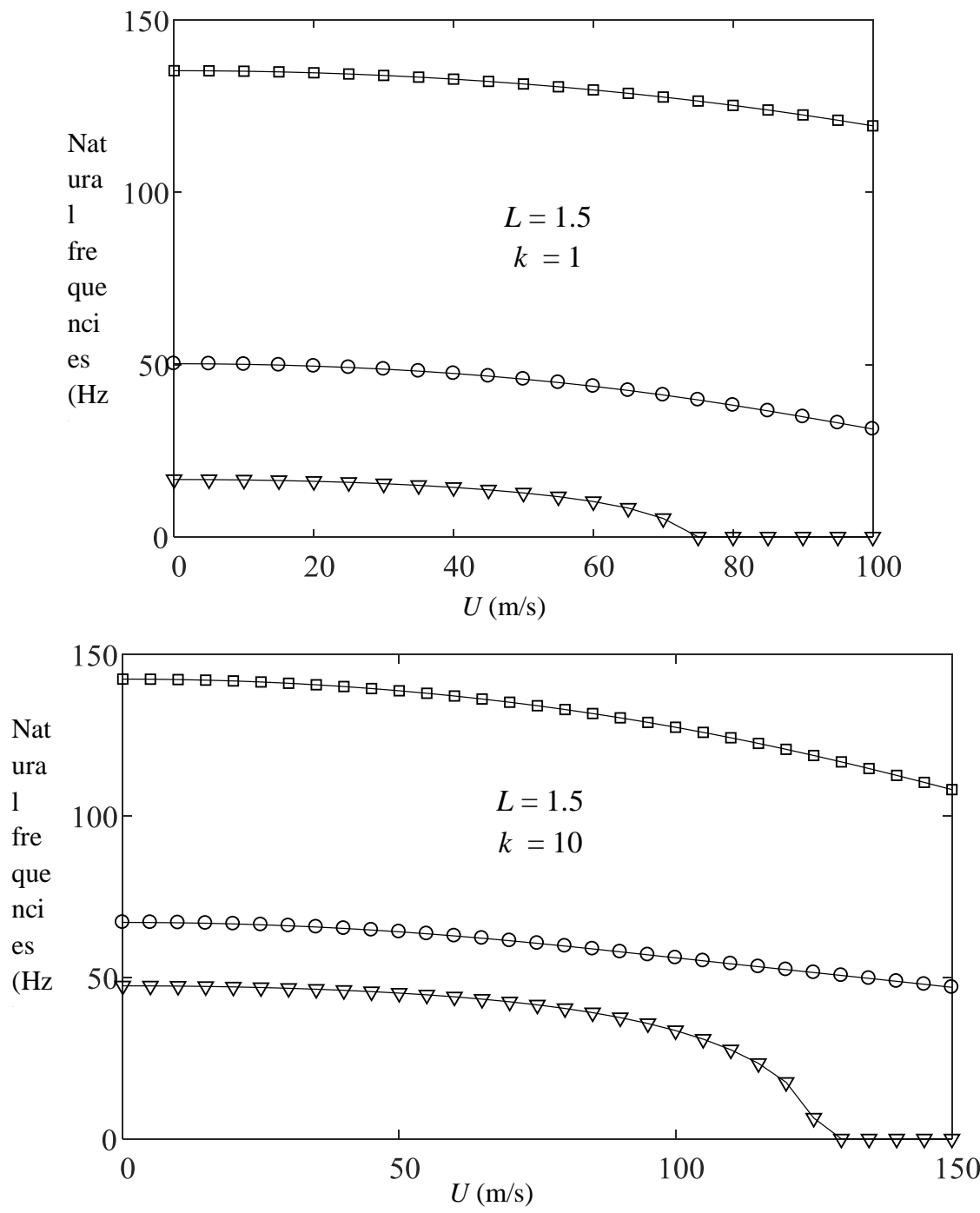

Figure 9: Effect of foundation stiffness on the natural frequency of the clamped-free pipe at different fluid velocities, $L=1.5, \beta=0.5$

By studying dynamics (Flutter) where the critical velocity varies according to the masse ratio in interval [0.1 0.7] see(figure10), we find that the variation curve takes a hyperbolic form. The figure 13 shows the variation of the critical velocity as a function of the length; we note that this curve has the same shape as the curve previous figure (11). We found here that the parameter $\beta$ has a destabilizing effect.Critical velocity is very sensitive to variation in length. The figure 12 represents the influence of the length on the variation of the critical velocity for different stiffness with different mass ratio. For $k=1$, we find that the slopes straighten around $L=1.5$. We repeated the same work for $k=10$, the curve have the same gaits. 


\subsection{Pipe instability parameters}

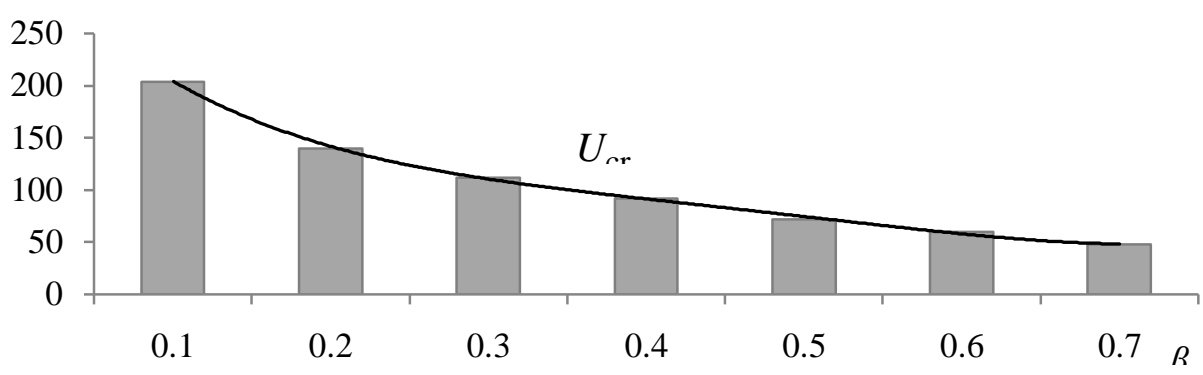

Figure 10 : L'évaluation de la vitesse critique de l'instabilité en fonction du rapport de masse pour une longueur de référence $L=1$.

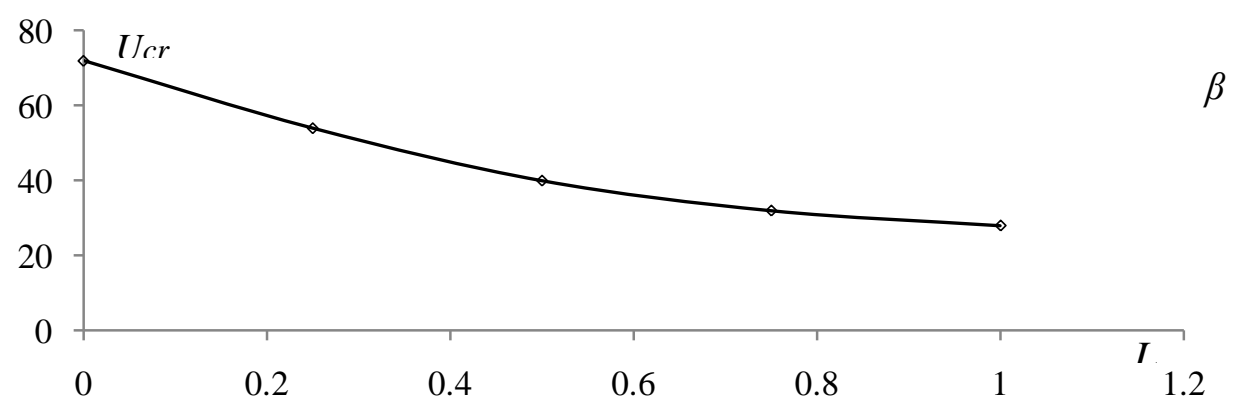

Figure 11 : Courbe de l'instabilité du tuyau encastré-libre, mise en évidence de l'effet déstabilisant de la longueur du système.
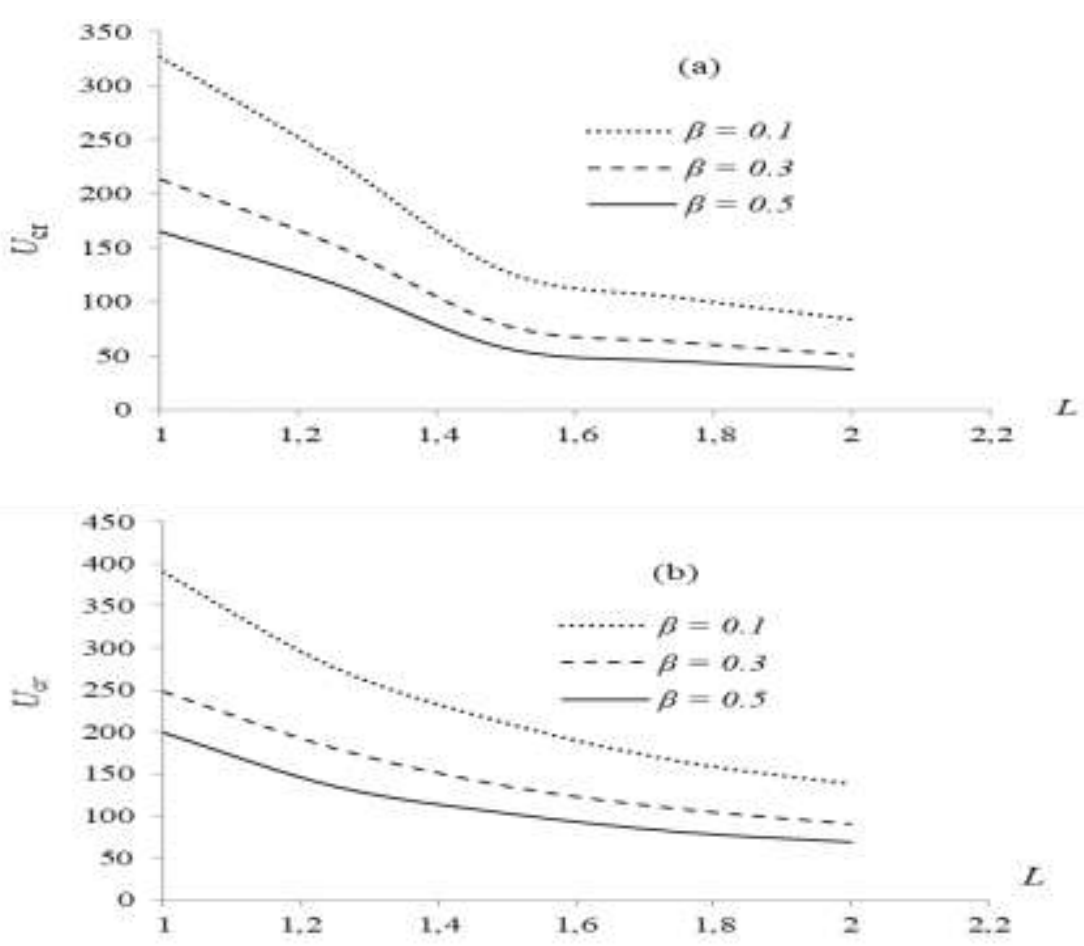

Figure 12 : Courbes de l'instabilité du tuyau encastré-librepour différentes fondations élastiques, mise en évidence de l'effet déstabilisant de la longueur et de l'effet déstabilisant du rapport de masse, (a) $k=1$, (b) $k=10$. 


\section{Conclusion}

The numerical aspect gives solutions in complex planes by determining the eigen-modes, an imaginary part to present the eigen-frequencies according to the fluid velocity for various parameters. The first observation that we can make that the natural frequencies of the system depends on the fluid velocity. We observe that instability appears when the velocity exceeds a threshold called the critical instability velocity. The critical velocity of the fluid varies according to the mass ratio, and translates the stability of our system, while the foundation increases the system rigidity and consequently the natural frequencies and the critical speed. It has been observed that there is an absence of static buckling instability.

\section{$5 \quad$ Reference}

[1] Païdoussis M.P., 1970, Dynamics of tubular cantilevers conveying fluid. Journal Mechanical Engineering Science, 12 (2), 85-103.

[2] Païdoussis M.P., Besancont P., 1981, Dynamics of arrays of cylinders with internal and external axial flow. Journal of Sound and Vibration, 76 (3), 361-379.

[3] Païdoussis M.P., 1981, Fluidelastic vibration of cylinder arrays in axial and cross flow: state of the art. Journal of Sound and Vibration, 76 (3), 329-360.

[4] Païdoussis M. P., Curling LL. R., 1985, An analytical model for vibration of clusters of flexible cylinders in turbulent axial flow. Journal of Sound and Vibration, 98 (4), 493-517.

[5] Païdoussis M.P., Moon F. C., 1988, Nonlinear and chaotic fluidelastic vibrations of a flexible pipe conveying fluid. Journal of Fluids and Structures, 2, 567-591.

[6] Païdoussis M.P., Semler C., Wadham -Gagnon M., Saaid S., 2007, Dynamics of cantilevered pipes conveying fluid. Part 2: Dynamics of the system with intermediate spring support. Journal of Fluids and Structures, 23, 569-587.

[7] Païdoussis, M.P; Li, G.X, 1993, Pipes conveying fluid: a model dynamical problem. Journal of Fluids and Structures, 8, 137-204.

[8] Païdoussis, M.P, 1998, Fluid-structure interactions slender structures and axial flow, Department of Mechanical Engineering. Academic Press, volume 1.

[9] Doaré O., De Langre E., 2002, Local and global instability of fluid-conveying pipes on elastic foundations. Journal of Fluids and Structures, 16 (1), 1-14.

[10] Doaré O., De Langre E., 2002, The flow-induced instability of long hanging pipes. European Journal of Mechanics A/Solids, in press.

[11] Doaré O., De Langre E., 2000, Local and global instabilities of fluid-conveying cantilever pipes. Flow-Induced Vibration, 349-354.

[12] Doaré O, De Langre E., 2006, The role of boundary conditions in the instabilityof onedimensional systems. European Journal of Mechanics B/Fluids, 25 (6), 948-959.

[13] Chellapilla K.R., Simha H.S., 2007. Critical velocity of fluid-conveying pipes resting on two parameter foundation. Journal of Sound and Vibration, 302, 387-397.

[14] Chellapilla K.R., Simha H.S., 2008. Vibrations of fluid-conveying pipes resting on twoparameter foundation. The Open Acoustics Journal, 1, 24-33.

[15] Qian Q.,Wang L.,Ni Q., 2009, Instability of simply supported pipes conveying fluid under thermal loads. Mech.Res.Commun, 36(3), 413-417

[16] Ni Q., Zhang Z.L., Wang L., 2011, Application of the differential transformation method to vibration analysis of pipes conveying fluid. Applied Mathematics and Computation 217, 7028-7038.

[17] Morteza, H. Sadeghi, Mohammad, H. Karimi-Dona, 2011, Dynamic behavior of a fluid conveying pipe subjected to a moving sprung mass-An FEM-state space approach. International Journal of Pressure Vessels and Piping 88: 123-131. 
[18] Mostapha, N.H, 2014, Effect of a viscoelastic foundation on the Dynamic stability of a fluid conveying pipe. International Journal of Applied Science and Engineering, 12(1): 5974.

[19] Dahmane, M., Boutchicha, D.,Adjlout, L., 2016, One-way fluid structure interaction of pipe under flow with different boundary conditions. MECHANIKA.,22(6), 495-503.

[20] Rao S.S., 2004, The finite element method in engineering. 4thed, Elsevier Science \& Technology Books. 